EGU2020-9804

https://doi.org/10.5194/egusphere-egu2020-9804

EGU General Assembly 2020

(c) Author(s) 2021. This work is distributed under

the Creative Commons Attribution 4.0 License.

\title{
Impacts of bottom trawling on benthic trophic status and meiofauna in a deep-sea sedimentary environment (Gulf of Castellammare, southwestern Mediterranean Sea)
}

\author{
Antonio Pusceddu ${ }^{1}$, Sarah Paradis ${ }^{2,3}$, Davide Moccia ${ }^{1}$, Pere Puig ${ }^{3}$, Pere Masque ${ }^{2,4}$, Tommaso \\ Russo $^{7}$, Maria Carmela Meloni ${ }^{1}$, and Claudio Lo lacono ${ }^{3,4}$ \\ ${ }^{1}$ Dipartimento di Scienze della Vita e dell'Ambiente, Università degli Studi di Cagliari, Cagliari, 09126, Italy \\ (apusceddu@unica.it) \\ ${ }^{2}$ Institut de Ciència i Tecnologia Ambientals, Universitat Autònoma de Barcelona, Bellaterra, 08193, Spain \\ ${ }^{3}$ Marine Sciences Institute, Consejo Superior de Investigaciones Científicas, Barcelona, 08003, Spain \\ ${ }^{4}$ Departament de Física, Universitat Autònoma de Barcelona, Bellaterra, 08193, Spain \\ ${ }^{7}$ Laboratory of Experimental Ecology and Aquaculture, Department of Biology, University of Rome Tor Vergata, Rome, \\ 00133, Italy
}

The impacts of bottom trawling on the structure of benthic communities can be relatively nonselective, hitting biodiversity as a whole. This holds true also in the deep sea, where the impacts of trawling can be more severe and long-lasting than in shallow-waters, due to the reduced capacity for recovery and greater vulnerability of deep-sea organisms. For years, our knowledge of the impact of trawling on deep-water ecosystems has remained limited and has focused mainly on fish stocks and hard bottom systems. More recently, a number of studies have addressed the impacts of bottom trawling in the deep-sea sedimentary environments, and very few of them have focused on the impacts on meiofauna, though it is a key faunal component of deep-sea ecosystems.

We investigated the impact of bottom trawling on the quantity, biochemical composition and nutritional value of sedimentary organic matter and meiofauna along the Sicilian Margin (Gulf of Castellammare, southwestern Mediterranean) at ca. $550 \mathrm{~m}$ depth, during the summer of 2016. Amount, biochemical composition and freshness of sedimentary OM, as well as the abundance and community composition of meiofauna were determined in sediment cores taken at both trawled and untrawled grounds. The continuous erosive processes in the trawled site have led, generally, to the depletion of OM contents (20-60\% lower than those in the untrawled site), as well as to statistically significant differences from the untrawled site in its biochemical composition. Nevertheless, the upper $2 \mathrm{~cm}$ of the trawled site consisted of recently accumulated sediments, enriched in phytopigments, and bulk OM contents similar to those in the untrawled one, interpreted as a very recent input of fresh OM from the upper water column. The abundance of meiofauna in trawled grounds was significantly higher than that in untrawled ones, whereas no differences were observed between trawled and untrawled grounds deeper in the sediment. Differences in the meiofaunal community composition among sediment layers in each site were 
larger than those among sites.

As previously reported, deep bottom trawling in the Gulf of Castellammare erodes large volumes of sediment, exposing old compacted sediment that is depleted in OM. This erosive action generally prevents the accumulation of fresh sediment. However, the episodic short-lived deposition of fresh organic detritus between hauls can lead to a temporary accumulation of fresh and bioavailable OM which, in turn, can induce a positive response in meiofauna abundance.

These results pinpoint the need of considering the impacts of bottom trawling on the benthic communities of deep-sea sedimentary environments at temporal scales shorter than previously done. 